\title{
TMS Members Selected for Presidential Subcommittee; Explore the Redesigned TMS Webinar Library
}

\section{Presidential Council Selects Two TMS Members for New Subcommittee}

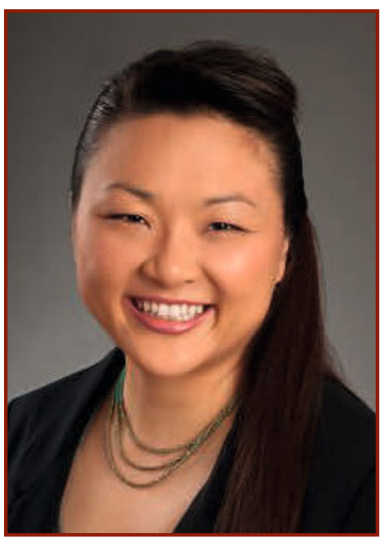

Kiyo Fujimoto

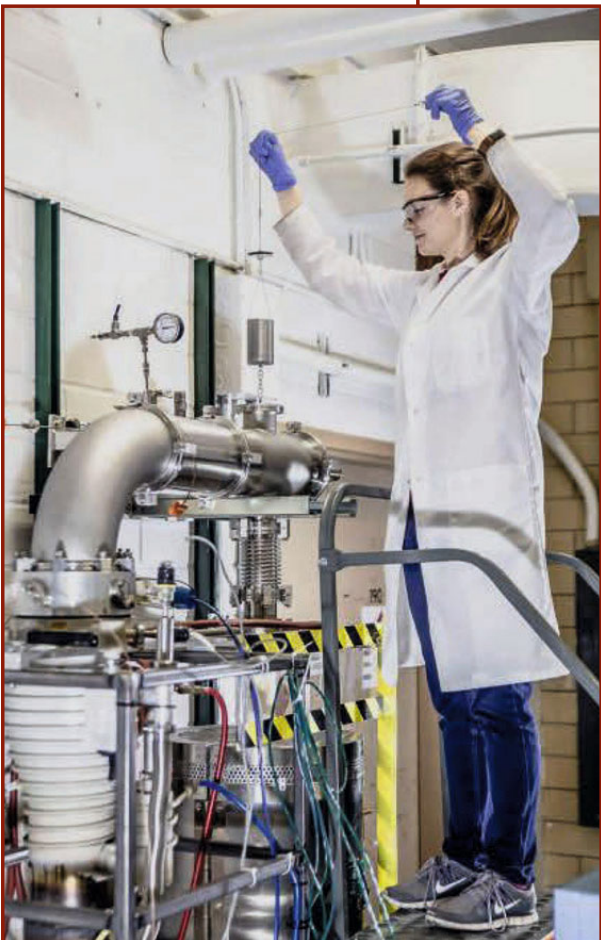

011, PCAST "makes

policy recommendations

in the many areas where

understanding of science,

technology, and innovation

is key to strengthening our economy and forming policy that works for the American people," according to the U.S. Office of Science and Technology Policy.

Fujimoto is pursuing her $\mathrm{Ph} . \mathrm{D}$. in materials science and engineering at Boise
State University (BSU) and working as a graduate fellow at Idaho National Laboratory. "It is exciting to know that my experiences and input can be utilized to potentially improve the STEM experience for current and future generations of scientists and engineers," Fujimoto said in a BSU announcement. Her current research focuses on 3D printing for the development and fabrication of advanced nuclear instrumentation and sensors. She has been a TMS member since 2020 .

"I want to help create a positive and supportive environment for future scientists," said Rinko, noting her excitement at accepting the position in an announcement from Ames Laboratory. Rinko is currently a Ph.D. candidate at Iowa State University studying materials science and engineering, specifically focusing on AlNiCo magnets. She also works as a graduate research assistant at Ames Laboratory. As a TMS member since 2018, Rinko is involved in the Public \& Governmental Affairs Committee and Powder Materials Committee.

\section{Emily Rinko}

(Photo credit: Ames Laboratory)

\section{member news}

Share the good news about your professional accomplishments! Contact Kaitlin Calva, JOM Magazine Managing Editor, at kcalva@tms.org. Please note that only news submitted by current TMS members will be considered. 


\section{See What's New in the TMS Webinar Library}

The newly redesigned TMS Webinar Library features a variety of topics, from fundamentals and emerging technologies, to developing business and leadership skills, to recent advancements and current issues impacting the breadth of materials science and engineering. The library includes 12 new programs recorded in 2020 alone, with new content in development for 2021 at press time, as well as access to webinars recorded in 2018 and earlier. Enhancements to the resource include the ability to search for webinars by keyword, presenter, or event title, and to view past webinar recordings directly through the TMS website.

As an exclusive benefit, TMS members can access live or recorded events for free. Members can log in at www.tms.org/ WebinarLibrary to access webinar content.

If another topic would fit your interests and needs, TMS is accepting ideas for new webinars. Simply click the "What New Content Do You Need?” button on any webinar page to provide suggestions for new programs through our Online Learning Resources Survey.

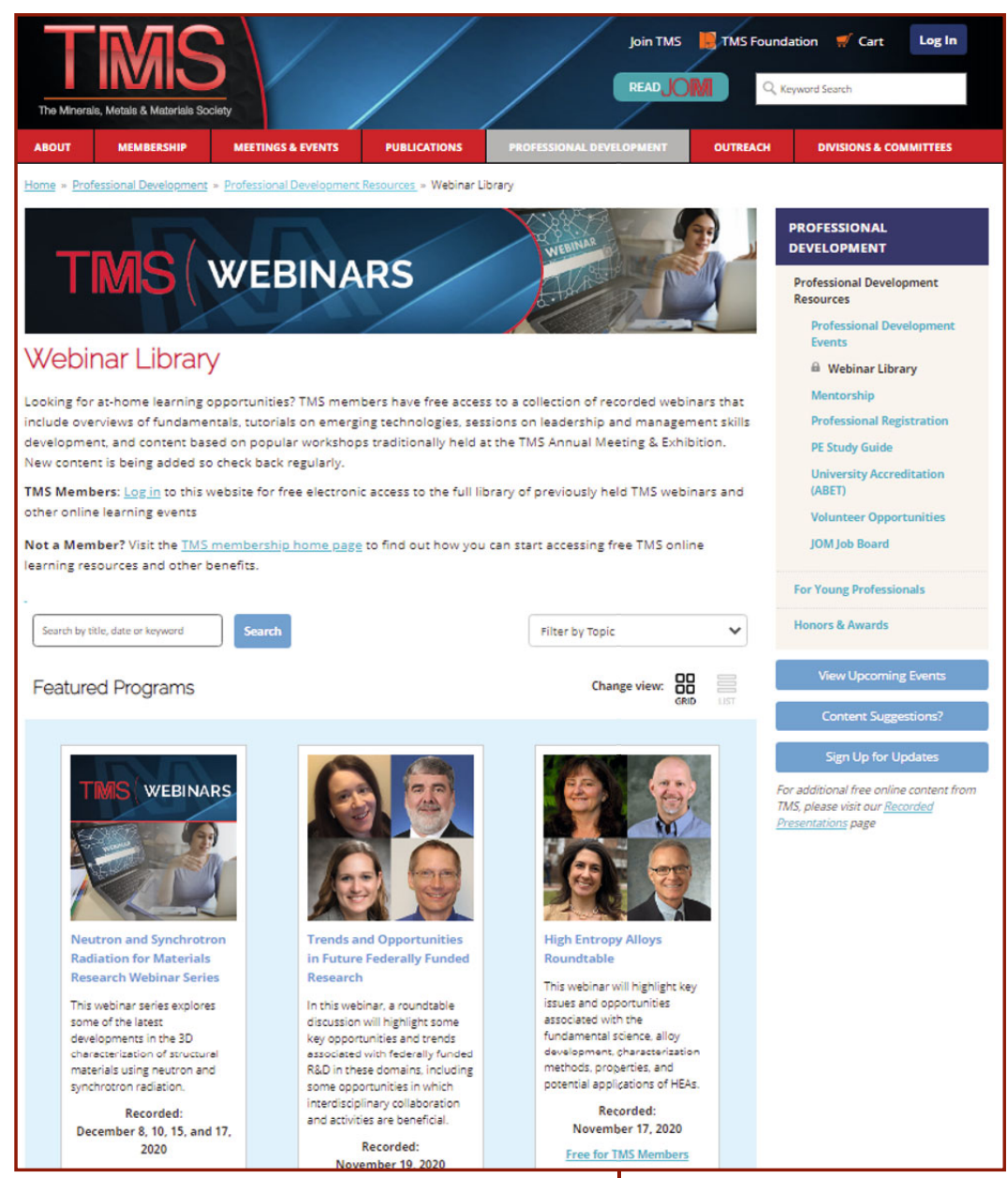

\section{Updated Impact Factor for JOM}

In October 2020, the 2019 Impact Factor for $J O M$ was adjusted from 2.029 to 2.054. The update came after a small number of articles were moved to the appropriate indexing category. For more details on the Impact Factors for all TMS journals, read the September 2020 JOM article, "Impact Factors and Other Key Metrics Released for All Six TMS Journals."

\section{Announcing the 2021 TMS Meeting of the Membership and Open Board of Directors Meeting}

The Minerals, Metals \& Materials Society, Inc., in accordance with its bylaws (Article II, Section 2.6, and Article III, Section 3.7) will hold the 2021 Annual Meeting of the Membership with Open Board of Directors Meeting in conjunction with TMS2021 Virtual, on Thursday, March 18, 2021, from 11:00 a.m. to noon (ET), via GoToWebinar.

Registration is required by March 11. Attendance is limited. All TMS members are welcome to attend, and valid TMS membership is required. The event is free, and TMS2021 Virtual registration is not required.

To register visit www.tms.org/2021TMSMeetingOfTheMembership. The meeting will be recorded with the intent to post it to the TMS web site. 